УДК 781.7

\title{
ЦЗИ ЯньИ
}

Российский государственный педагогический университет имени А. И. Гериена Институт музыки, театра и хореографии

2. Санкт-Петербург, Россия

ORCID: 0000-0002-8177-9911,332911934@qq.com

\section{Китайская бамбуковая фмейта: история и конструктивные особенности}

В данной статье охарактеризованы особенности китайского флейтового творчества и способы технологии изготовления китайской бамбуковой флейты, а точнее - флейты «сяо» (萧). Автор описывает особенности конструкции и материалов для данных флейт, рассказывает историю одного из наидревнейших музыкальных инструментов, известных человечеству. Показаны причины её распространения, изученные и предложенные непосредственно автором. Обсуждаются принципы звукоизвлечения, манера игры, различные варианты флейты. Автор рассказывает о символическом и культурном значении бамбука в Китае. Описывается значение и символика самой флейты, подтверждение чему мы находим в древних китайских текстах, в то время как само искусство (в том числе и флейтовое) для китайцев это - «дао, выраженное в чувствах». На современном этапе в Китае искусство игры на сяо приобрело массовый характер. Растёт технический уровень сольных и ансамблевых вариантов музицирования на этом инструменте. Флейту используют не только в традиционных ансамблях, но и в авторской музыке современных композиторов. В этом простом инструменте запечатлены отголоски древней музыкальной культуры. Вместе с тем сяо оказалась удивительно близка художественным запросам современности.

Ключевые слова: флейта, бамбуковая флейта, изготовление флейты, конструкция флейты, Китай.

Для циттирования / For citation: Цзи Яньи. Китайская бамбуковая флейта: история и конструктивные особенности // Проблемы музыкальной науки / Music Scholarship. 2021. № 2. C. 86-93. DOI: 10.33779/2587-6341.2021.2.086-093.

(С) Цзи Яньи, 2021

(c) Издатель: АНО ДПО НМЦ «Инновационное искусствознание», 2021

\section{JI YAN YI}

Herzen State Pedagogical University of Russia Institute of Music, Theater and Choreography

St. Petersburg, Russia ORCID: 0000-0002-8177-9911,332911934@qq.com

\section{The Chinese Bamboo Flute: History and Constructive Traits}

This article gives a characterization of the specific features of the Chinese art of flute performance and the methods of manufacturing the Chinese bamboo "Xiao" flute [萧]. The author describes 
the specificity of the construction of and materials for this type of flute and recounts the history of the flute - one of the most ancient musical instruments known to mankind. The reasons for its broad popularity and dissemination, as researched and defined by the author, are discussed. The principles of playing this flute, the different manners of performance, as well as the different versions of the instrument are elaborated. The author recounts about the symbolic and cultural significance of bamboo in China. The meaning and symbolism of the flute itself are demonstrated, confirmations of which are cited in ancient Chinese treatises; at the same time art (including the art of flute playing) for the Chinese is demonstrated as the "Tao expressed in feelings." At the modern stage, the art of playing the Xiao flute has acquired a mass character in China. The technical skill of solo and ensemble varieties of performance on this instrument is greatly accumulating. Not only traditional ensembles, but also music written by modern composers, make use of the Xiao flute. The echoes of ancient musical culture are imprinted in the sound of this small instrument. At the same time, the Xiao flute has also demonstrated itself as being remarkably close to the artistic demands of modern times.

Keywords: flute, bamboo flute, flute manufacturing, construction of the Xiao flute, China.

(C) Ji Yan Yi, 2021

(C) Publisher: Scholarly-Methodical Center “Innovation Art Studies,” 2021

$\mathrm{K}$ итайское музыкальное искусство формировалось на протяжении многих тысячелетий под воздействием различных направлений музыки как исконно китайской, так и соседних с Китаем регионов: Центральной Азии, Индии, Монголии. Кроме того, в Китае проживают различные нации и народности, которые также внесли вклад в развитие традиционного китайского музыкального искусства.

Китайская флейта - один из старейших и наиболее распространённых традиционных инструментов Китая. Бамбуковая флейта наиболее известна в Китае и Японии, поскольку именно там это растение встречается чаще всего, тогда как в Центральной Америке флейты издавна изготовлялись из тростника. Среди инструментов западноевропейской культуры, освоенных музыкантами Китая в XX столетии, флейта занимает особое положение. Связано оно с тем, что в Китае существует немало их разновидностей, активно ис- пользуемых в практике традиционной музыки. Они сильно отличаются от европейского аналога и заключают в себе звуковой образ родной культуры. Изготовленные из бамбука или камыша, они обладают негромким, но весьма выразительным звучанием [6].

Представляющая огромное значение для истории и культуры Китая, китайская бамбуковая флейта совершенно не рассматривается в русскоязычных исследовательских работах. В данной статье впервые на русском языке будет очерчена история развития бамбуковой флейты, представлены конструкция и ряд основополагающих конструктивных особенностей бамбуковой флейты, показаны основные принципы звукоизвлечения.

Все бамбуковые флейты звучат в пентатонике, и звукоряд каждой начинается с различного тона. Всего существует 12 типов бамбуковых флейт. Среди них есть пять флейт Бангди (梆笛), играющих в минорной пентатонике от B, A, G, 
F и Е. Есть и пять флейт гуди (曲笛) со следующими настройками: $\mathrm{C}, \mathrm{D}, \mathrm{C}, \mathrm{b}-\mathrm{B}$, A, G. Кроме того, есть также и флейта c настройкой $\mathrm{F}$, которая используется редко - это самая большая флейта, которая недоступна для большинства музыкантов, в виду требований иметь нестандартную величину рук.

Для новичков, посредством преобразования аппликатуры и смены тона, в основном достаточно 5 бамбуковых флейт (C, D, E, F, G). Существует 5 типов аппликатуры для флейты, которые меняются в зависимости от требуемой силы звука (звук продувается, когда все отверстия закрыты). Звуковой диапазон будет меняться в разных настройках. Например, на бамбуковой флейте с настройкой C можно играть в $\mathrm{C}, \mathrm{F}, \mathrm{G}, \mathrm{D}$, B-E и одноимённых минорах. (10 тонов можно играть изначально, но, открыв полуотверстия (аппликатура), вы сможете сыграть 14 тонов). Причина, по которой существует так много флейт, заключается в том, что стили мелодии отличаются, и тональный эффект требуется разный. В крупных национальных оркестрах обычно 4-5 человек играют на флейтах разного тона.

Процессы вестернизации, охватившие музыкальные запросы стран Азии в первой половине XX века, способствовали приятию вместе с тембровыми красками симфонического оркестра его духовых инструментов, и среди них - флейты. Однако западный образец, пожалуй, быстрее всех других инструментов оказался вовлечённым в орбиту соединения традиций - инокультурной и национальной [2]. На флейте легко и быстро китайские музыканты «заговорили» на «родном» языке, поручая ей не только народные наигрыши и напевы, но и воплощая в игре в созданных для неё произведениях специфические тембро- вые, интонационные, артикуляционные тонкости. Так, западная флейта оказалась на пути слияния двух традиций задачи, которую сознательно ставили перед собой музыканты и педагоги Китая. Процесс её вовлечения в национальную музыкальную культуру имел определённые исторические этапы и свойственные им характеристики.

В отличие от западной, бамбуковая флейта сохранялась всё время в культуре Китая, соперничая с костяной флейтой Ди (骨笛). Однако, со временем (в период династии Шань, XVI-XI в. до н. э.; к данному времени относится немало найденных бамбуковых флейт) бамбуковая флейта, однако, полностью вытеснила костяную, что, на наш взгляд, объясняется следующими причинами:

1) акустические возможности в частности, частота вибрации (а следовательно, и громкость, и интенсивность звука) у бамбуковой флейты выше, чем у костяной, да и сам звук является менее свистящим и резким;

2) бамбуковая флейта легче в изготовлении; её проще вытачивать и обрабатывать в силу большей мягкости дерева. Наконец, можно предположить, что редкость журавля (сегодня он уже занесён в Красную книгу), из крыльев которого делалась костяная флейта, также сыграла роль по отношению к факту повсеместного распространения бамбуковой флейты. Согласно одному из наиболее общепринятых мнений, во времена династии Чжоу (1046-1256 до н. э.) флейта приобрела более или менее окончательный вид, близкий её сегодняшней версии [1, c. 19].

Бамбук с древних времён почитается китайскими мудрецами, как растение, наделённое магическими свойствами. Бамбук, размещённый в жилище, приносит защищённость ему от злых духов. 
Это почитаемое растение используется в искусстве, воспевается в поэзии и часто упоминается в литературе китайской нации.

Считается, что бамбук символизирует долгожительство и выносливость, ведь он остаётся зелёным весь год. Каждая последующая секция в бамбуковой флейте обычно длиннее предыдущей, что сопутствует поэтапному улучшению жизни. Стебли бамбуковых растений имеют мощный и быстрый рост, это ассоциируется с удачей и успехом в делах и начинаниях, несёт в себе положительную энергию для развития и благополучия. Бамбуковая флейта, как символ просветления и озарения, приносит духовное благословение.

История китайского народного инструмента бамбуковой флейты, по официальным источникам, насчитывает более трёх тысячелетий. На самом деле он существует столько же, сколько и человечество, потому что относится к одному из самых первых видов музыкально-сигнальных инструментов в жизнедеятельности homo sapiens.

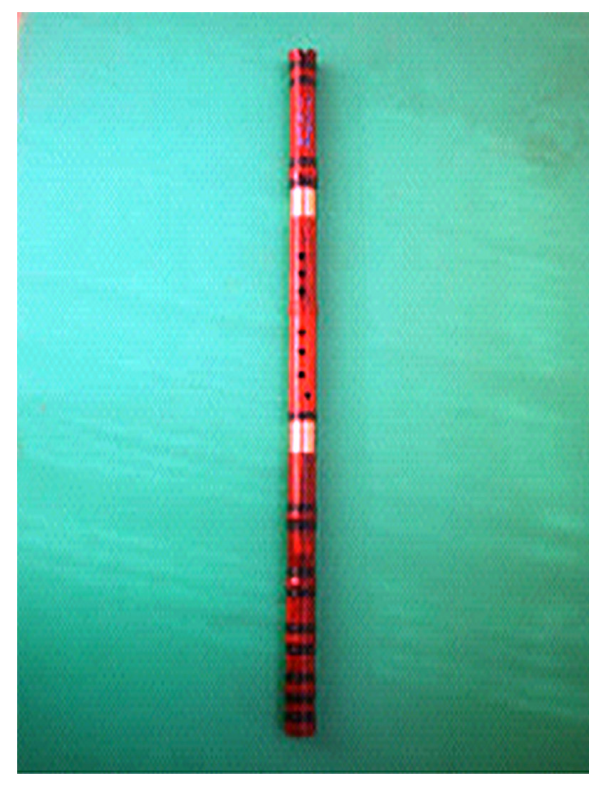

И^. 1. Ф^ейта сяо [9, с. 31]
Сяо - продольная бамбуковая флейта, получившая своё название в период династии Тан (618-907). Одно из первых упоминаний о китайской флейте относится к династии Цинь (221-207 до н. э.): это был сяо с 3-4 отверстиями. В эпоху Хань (207 до н. э. 220 н. э.) было добавлено 5-е отверстие. К 247 году в период династии Вэй (220$265)$ флейта сяо имела 6 отверстий и по форме стала приближена к современной, а в XX веке появились инструменты с 8 отверстиями [8].

Поскольку эту флейту сравнительно легко изготовить, она была и остаётся очень популярной в Китае. Обычно сяо создают из бамбука, но встречаются и каменные (из жадеита или нефрита), фарфоровые, из слоновой кости и дерева. Напомним, что бамбук в Китае считается священным растением, которое призвано защищать, дарить долголетие и здоровье, приносить удачу и исполнять желания. Он выбран в качестве материала для флейты, подобно тростнику, крапиве, куге, болотному камышу и пыляне в других культурах, так как эти растения имеют полый ствол.

Для сяо используется бамбук определённого сорта. Технология производства отработана веками: прогрев нижнего участка ствола, затем примерно недельное просушивание, во время которого должны испариться натуральные масла, а окраска измениться с зелёной на светло-коричневую. Главный этап - выдержка трубки от трёх до шести лет. После этого - тщательная ручная работа, превращающая полую трубку в музыкальный инструмент, приобретающий неповторимый тембр и характер звучания. У китайцев есть поверье, что звуки сяо подобны дыму, который может проникать в иные пространства, представляя собой специфический способ медитации. 
Во времена династий Суй (581-618) и Тан (618-907) отмечается активное развитие музыкальных инструментов, приведшее к значительным достижениям китайской музыкальной культуры. Так, например, в эпоху династии Тан в Китае использовалось около 300 различных видов, среди которых по удобству изготовления и исполнения лидировала флейта сяо.

Памятники древности (живопись, архитектура, скульптура) демонстрируют доминирующее значение игры на данном инструменте в основном среди женского населения, что относится не только к флейте сяо, но и ко многим другим. Говоря в целом о формах сольного или ансамблевого музицирования в древние времена, можно с уверенностью констатировать, что во многих традиционных культурах главными исполнителями являлись женщины: в Древнем Египте и Греции, славянской традиции игра на духовых инструментах принадлежала женщинам.

Материалом для изготовления флейты служат полые суставчатые стебли локальных для каждой традиции разновидностей дикорастущих зонтичных растений. Так, например, в России это куга, на Урале и в Перми - вольгум пикан, пылян (отсюда название инструментов кугиклы, пыляны). Могли также использовать перья крупных водоплавающих птиц (лебедя, гуся) и т. д. Для изготовления одноразового инструмента специальная подготовка материала не требуется, для долговременного инструмента травяные стебли сушат и обрабатывают. Самый древний экземпляр такой флейты (кена) обнаружили на территории Перу и Боливии, возраст которого более 10 тысяч лет.

В китайских мифах и легендах отражено особое воздействие музыки на при- роду и человека. Роль сяо в китайском эпосе своеобразна: с помощью её звуков можно было вызвать дождь, повлиять на цветение и рост растений, сформировать доблесть и героизм воина, очистить жилое пространство от злых духов и т. п. [12]. Музицирование на флейте сяо требует определённых навыков, связанных с душевным состоянием исполнителя, поскольку данный инструмент, по убеждению музыкантов, помогает очистить разум и достичь спокойствия сознания. Более того, дыхательная техника игры на сяо связана с традиционной китайской психофизиологической практикой цигун, являющейся частью боевых искусств. Эту специфику дыхания хорошо знают флейтисты, владеющие искусством игры на сяо.

Для строения китайской флейты характерно деление на 2 части: верхняя, в корпусе которой имеются 6-7 отверстий (одно под большой палец, позволяющее облегчить исполнение в натуральном строе), украшенных кольцами из нитей, покрытых чёрным лаком. Нижняя часть сяо представляет собой закрытый торец, на конце которого расположена небольшая щель-свисток.

Звукоизвлечение происходит при направлении воздуха на срез свистка: флейтист, не прикасаясь губами к флейте, упирает её в ложбинку подбородка и дует в свисток с некоторого расстояния. Звук сяо насыщен мягкой тембровой окраской, его сравнивают с шелковистым бархатом, медленно стелющимся дымом, который проникает в другие миры. Именно поэтому игра на сяо в китайской традиции трактуется как форма медитации, очищающая разум и дарующая просветление. Средний размер сяо достигает 75-80 см, но в разных регионах страны длина инструмента может варьироваться в пределах 50-70 см. 
Конструкция свистка представляет собой пробку со срезом, способствующую приданию звукам нежности и мягкости. Данное отверстие закрыто тоненькой пленкой из камыша или тростника, peзонирование которой придаёт звучанию флейты звонкость и сочность. Музыкальный строй у сяо пентатонический с диапазоном около двух октав: от $\mathrm{d}^{1}$ до $\mathrm{e}^{3}$.

В традиционном Китае музыка занимает высокое положение, долгое время она играла первостепенную роль в сакральных церемониях, в том числе стала и важной частью даосских религиозных ритуалов. Музыкальное сопровождение в даосских церемониях выполняет ряд важных функций, что и обусловливает необходимость её рассмотрения.

Так как музыка прочно связана со сферой сакрального, то для её характеристики необходимо обращение к концептам даосизма. Даосизм считается не только национальной религией, но и первоистоком самобытной музыкальной культуры Китая. Основные положения даосизма приведены в так называемом «Даосском каноне» («Даоцзан»), который переводится как «Сокровищница Дао» и состоит из 1476 текстов [2].

В настоящее время в каждом монастыре организованы специальные хранилища, в которых находятся канонические тексты «Даоцзан». Следует отметить, что на русский язык переведена лишь их незначительная часть. Искусство для китайцев - это дао, выраженное в чувствах [4].

Сегодня флейтовая культура в Китае характеризуется появлением модернизированного инструмента, что в свою очередь повлияло на устоявшиеся в стране эстетические представления об инструменте. В данном контексте возможно сравнение со скрипками, однако китайская эрху, как и всё её семейство, чересчур далека от своего европейского квазианалога - ничего общего, кроме наличия струн и смычка у этих инструментов нет.

С флейтой иная ситуация: китайские тростниковые или бамбуковые флейты известны во всём мире, их звучание перекликается со многими аналогами, в том числе европейской блокфлейтой. Виртуозность этих инструментов не уступает европейской флейте, однако природа техники и самого звучания иная.

Мелодии китайской флейты культивируют иные характеристики, нежели те, которые воплощает флейта из Европы. Отдельное внимание этому вопросу уделил Цуй Фохуа, рассматривая такие качества звучания, как флейтовое вибрато и сонорную динамику тона (см.: [5, с. 7]).

На современном этапе в Китае искусство игры на сяо приобрело массовый характер. Растёт технический уровень сольных и ансамблевых вариантов музицирования на этом инструменте. Флейту используют не только в традиционных ансамблях, но и в авторской музыке современных композиторов. В этом простом инструменте запечатлены отголоски древней музыкальной культуры. Вместе с тем сяо оказалась удивительно близка художественным запросам современности. Китайский музыкант находит в ней способ быстрого приобщения к искусству широких масс; западный же слушатель воспринимает флейту сяо как олицетворение колористической самобытности Востока. 


\section{Or АИТЕРАТУРA $\checkmark$}

1. Кухарский В. Музыка свободного Китая // Советская музыка. 1959. № 8. С. 170-180.

2. Сиднева Т. Диалектика границы в музыке. М.: ABCdezign, 2014. 400 с.

3. 王国安一从实践到解决：我国学校音乐教育的改革与发展/王国安 广州, 2005. 273 页 [Ван Гоань. От практики до решения: реформа и развитие музыкального образования в школах нашей страны. Гуанчжоу: Хуачэн, 2005. 273 с.].

4. 李学全. 等待国内的长笛//乐器, 2000. 1, 第23 - 25页 [Ли Сюэцюань. В ожидании отечественной флейты // Музыкальные инструменты. 2000. № 1. С. 23-25].

5. 陆星. 选择中国的长笛/陆星 北京：民族音乐出版社，2005. 158页 [Лу Син. Выбор китайской флейты. Пекин: Изд-во Народной музыки, 2005. 158 с.].

6. 刘萍. 长笛演奏艺术简史/刘萍 // 中国的科技财富 2010年 12 - 24页 [Лю Пин. Краткая история искусства игры на флейте // Научно-техническое богатство Китая. Пекин, 2010. C. 12-24].

7. 徐寒. 高校笛子的教学方法和音乐演奏分析/徐寒 // 商业文化 2011年-第6-13页 [Сюй Хан. Анализ методики преподавания и музыкального исполнения на флейте в высших учебных заведениях // Деловая культура. Пекин, 2011. С. 6-13].

8. 吴炜. 将西方乐器与民族文化融合 - 浅析黄梅戏中的长笛演奏 // 《黄中: 黄梅戏 的艺术，1996年第2期. 第37 - 38页 [У Вэй. Слияние западных музыкальных инструментов с национальной культурой - краткий анализ использования флейты в хуанмэйской опере // Хуанчжун: Искусство хуанмэйской оперы. 1996. № 2. С. 37-38].

9. 张东明. 谈论过去和现在的笛萧 // 乐器学报 2019年第6期, 第30-33页 [Чанг Дунгминг. Говоря о прошлом и настоячем сяо и ди // Журнал музыкальных инструментов. 2019. № 6. С. 30-33].

10. 陈建华. 管乐器手册/陈建华 - 上海：上海音乐出版社1999年 296页 [Чэнь Цзяньхуа. Справочник по духовым инструментам. Шанхай: Шанхайское муз. изд-во, 1999. 296 c.].

11. 杨艳丽. 伟大的声音 - 如何演奏长笛/杨艳丽 // 科技创新指南. 2011年-第 17 - 33页 [Ян Яньли. Прекрасный звук - как играть на флейте // Руководство по инновациям в области науки и техники. 2011. С. 17-33].

12. 严平. 关于长笛的形式和结构对艺术发展的影响的问题/阎平 // 中国北方音乐。 2011年-第7 - 11页 [Янь Пин. К вопросу о влиянии формы и структуры флейты на развитие искусства // Музыка Северного Китая. Хэйлунцзя́н, 2011. С. 7-11].

\section{Об авторе:}

Цзи Яньи, аспирантка кафедры музыкального воспитания и образования, Российский государственный педагогический университет имени А. И. Герцена, Институт музыки, театра и хореографии (198329, г. Санкт-Петербург, Россия),

ORCID: 0000-0002-8177-9911, 332911934@qq.com

\section{Or REFERENCES $\sqrt{0}$}

1. Kukharskiy V. Muzyka svobodnogo Kitaya [Music of Free China]. Sovetskaya muzyka [Soviet Music]. 1959. No. 8, pp. 170-180. 
2. Sidneva T. Dialektika granitsy v muzyke [The Dialectics of Boundaries in Music]. Moscow: AVSdezign, 2014. 400 p.

3. Wang Guo An. Cong shi jian dao jie jue:wo guo xue xiao yin yue jiao yu de gai ge yu fa zhan. Wang guo an - guang zhou, 2005. 273 ye. [Wang Guo An. From Practice to Solution: Reform and Development of Music Education in My Country's Schools. Guangzhou, 2005. 273 p.] (In Chinese)

4. Li Xue Quan. Deng dai guo nei de chang di. Yue qi, 2000. 1, di 23-25 ye. [Li Xue Quan. Waiting for the National Flute. Musical Instruments. January 2000, pp. 23-25.] (In Chinese)

5. Lu Xing. Xuan ze zhong guo de chang di. Lu xing - bei jing: min zu yin yue chu ban she, 2005. 158 ye. [Lu Xing. Choosing the Chinese Flute. Beijing: National Music Publishing House, 2005. 158 p.] (In Chinese)

6. Liu Ping. Chang di yan zou yi shu jian shi. Zhong guo de ke ji cai fu - 2021 nian. 12-24 ye. [Liu Ping. A Brief History of the Art of Flute Playing. China's Tech Fortune. 2010, pp. 12-24.] (In Chinese)

7. Xu Han. Gao xiao di zi de jiao xue fang fa he yin yue yan zou fen xi. Shang ye wen hua. 2011 nian di 6-13 ye. [Xu Han. Dizi Teaching Methods and Music Performance Analysis in Colleges and Universities. Commercial Culture. 2011, pp. 6-13.] (In Chinese)

8. Wu Wei. Jiang xi fang yue qi yu min zu wen hua rong he - qian xi huang mei xi zhong de chang di yan zou. Huang zhong:huang mei xi de yi shu,1996 nian di 2 qi. di 37-38 ye. [Wu Wei. Integrating Western Musical Instruments with the National Culture - An Analysis of Flute Playing in the Huangmei Opera. Huang Zhong: The Art of Huangmei Opera. 1996. No. 2, pp 37-38.] (In Chinese)

9. Zhang Dong Ming. Tan lun guo qu he xian zai de di xiao. Yue qi xue bao - 2019 nian di 6 qi, di 30-31 ye. [Zhang Dong Ming. Talking about the Past and the Present of Di Xiao. Journal of Musical Instruments. 2019. Issue 6, pp. 30-33.] (In Chinese)

10. Chen Jian Hua. Guan yue qi shou ce. Shang hai: shang hai yin yue chu ban she 1999 nian 296 ye. [Chen Jian Hua. A Handbook of Wind Instruments. Shanghai: Shanghai Music Publishing House, 1999. 296 p.] (In Chinese)

11. Yang Yan Li. Wei da de sheng yin - ru he yan zou chang di. Ke ji chuang xin zhi nan. 2011 nian - di 17-33 ye. [Yang Yan Li. Great Sound - How to Play the Flute. Technology Innovation Guide. 2011, pp. 17-33.] (In Chinese)

12. Yan Ping. Guan yu chang di de xing shi he jie gou dui yi shu fa zhan de ying xiang de wen ti. Zhong guo bei fang yin yue. 2011 nian - di 7-11 ye. [Yan Ping. A Question about the Influence of the Form and Structure of the Flute on the Development of Art. Northern China Music. 2011, pp. 7-11.] (In Chinese)

\section{About the author:}

Ji Yan Yi, Post-Graduate Student at the Department of Music Education, Herzen State Pedagogical University of Russia, Institute of Music, Theater and Choreography (198329, St. Petersburg, Russia), ORCID: 0000-0002-8177-9911, 332911934@qq.com

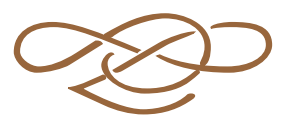

